\title{
Defining housekeeping genes suitable for RNA-seq analysis of the human allograft kidney biopsy tissue
}

\author{
Zijie Wang ${ }^{1}$, Zili Lyu², Ling Pan ${ }^{3}$, Gang Zeng ${ }^{4}$ and Parmjeet Randhawa ${ }^{4^{*}}$ (I)
}

\begin{abstract}
Background: RNA-seq is poised to play a major role in the management of kidney transplant patients. Rigorous definition of housekeeping genes (HKG) is essential for further progress in this field. Using single genes or a limited set HKG is inherently problematic since their expression might be altered by specific diseases in the patients being studied.

Methods: To generate a HKG set specific for kidney transplantation, we performed RNA-sequencing from renal allograft biopsies collected in a variety of clinical settings. Various normalization methods were applied to identify transcripts that had a coefficient of variation of expression that was below the 2nd percentile across all samples, and the corresponding genes were designated as housekeeping genes. Comparison with transcriptomic data from the Gene Expression Omnibus (GEO) database, pathway analysis and molecular biological functions were utilized to validate the housekeeping genes set.
\end{abstract}

Results: We have developed a bioinformatics solution to this problem by using nine different normalization methods to derive large HKG gene sets from a RNA-seq data set of 47,611 transcripts derived from 30 biopsies. These biopsies were collected in a variety of clinical settings, including normal function, acute rejection, interstitial nephritis, interstitial fibrosis/ tubular atrophy and polyomavirus nephropathy. Transcripts with coefficient of variation below the 2nd percentile were designated as HKG, and validated by showing their virtual absence in diseased allograft derived transcriptomic data sets available in the GEO. Pathway analysis indicated a role for these genes in maintenance of cell morphology, pyrimidine metabolism, and intracellular protein signaling.

Conclusions: Utilization of these objectively defined HKG data sets will guard against errors resulting from focusing on individual genes like $18 \mathrm{~S}$ RNA, actin \& tubulin, which do not maintain constant expression across the known spectrum of renal allograft pathology.

Keywords: RNA-sequencing, Kidney transplantation, Genes with housekeeping functions

\section{Background}

During the last decade, remarkable advances have been achieved in clinical medicine by the application of DNA microarray technology. Molecular signatures relevant to the diagnosis, prognosis and therapy have been discovered for numerous diseases [1-3]. In recent years, RNAsequencing (RNA-seq) has been recognized as an attractive alternate technology for the same purpose. Compared

\footnotetext{
*Correspondence: randhawapa@upmc.edu

${ }^{4}$ Department of Pathology, University of Pittsburgh Medical Center, E737 UPMC-Montefiore Hospital, 3459 Fifth Ave, Pittsburgh, PA 15213, USA Full list of author information is available at the end of the article
}

to microarrays, RNA-seq provides a more comprehensive profiling of the transcriptome, with better quantitation, over a wider dynamic range, while allowing single base resolution, and detection of isoforms, RNA editing events, microRNAs and long noncoding RNAs [4-6]. The technology has been refined sufficiently to allow mRNA profiling of single cells. Challenges among the application of RNA-seq in clinical medicine include the need for an experimental design that includes sufficient numbers of biologic and technical replicates, and implementation of a mathematically valid bioinformatics pipeline to mine the large volume of data generated at a reasonable cost $[7,8]$.

(c) The Author(s). 2019 Open Access This article is distributed under the terms of the Creative Commons Attribution 4.0 International License (http://creativecommons.org/licenses/by/4.0/), which permits unrestricted use, distribution, and reproduction in any medium, provided you give appropriate credit to the original author(s) and the source, provide a link to the Creative Commons license, and indicate if changes were made. The Creative Commons Public Domain Dedication waiver (http://creativecommons.org/publicdomain/zero/1.0/) applies to the data made available in this article, unless otherwise stated. 
The application of RNA-seq to the allograft kidney is at a very rudimentary stage. Rigorous definition of housekeeping genes (HKG) is essential for further progress in this field. HKG can be defined as genes ubiquitously expressed in all tissue compartments and cell-types regardless of their developmental stage, physiological condition and exposure to external stimuli [9]. HKG used in traditional clinical studies and classical biology experiments include 18S RNA, 28S RNA, tubulins, beta-actins, and glyceraldehyde-3phosphate dehydrogenase (GAPDH). However, it is known that the expression of these genes is not constant through the cell cycle, and is further altered in response to injurious stimuli. Indeed $18 \mathrm{~s}$ RNA Is one of the biomarkers associated with acute rejection [10]. Actin is upregulated in chronic allograft dysfunction [11]. Tubulin is targeted by Colchicine, a drug used in patients with gout: it inhibits microtubule polymerization by binding to tubulin and block mitosis by acting as a 'spindle poison' [12]. These examples illustrate how use of single genes or a limited set HKG can be inherently problematic.

One potential solution to the problem is to use bioinformatics techniques and derive large HKG data sets for evaluation of high throughput gene expression data. This will ensure that alteration of a small number of genes due to experimental conditions does not unfavorably affect the overall data analysis. Accordingly, this study has developed HKG gene sets appropriate for assessment of differential gene expression using nine different nine normalization methods that include library size, total counts (TC), upper quartile (UQ), Median, Quantile, trimmed mean of $\mathrm{M}$-values (TMM), reads per kilobase million (RPKM), transcripts per kilobase million (TPM) and DESeq. HKG lists are offered that are specific to particular normalization paradigms. In addition, there is a universal set of 42 housekeeping transcripts that are common to all nine individual analyses.

\section{Methods}

\section{Clinical material}

This study was approved by the University of Pittsburgh IRB (protocol \# 10110393). Formalin fixed paraffin embedded renal allograft biopsies $(n=25)$ were derived from recipients diagnosed with acute tubular injury (ATI; $n=5)$, T cell-mediated rejection (TCMR; $n=5$ ), interstitial fibrosis and tubular atrophy (IFTA; $n=5$ ), and BK virus-associated nephropathy (BKVN; $n=5)$, as well as recipients with stable allograft function (STA; $n=5)$. Five native kidney biopsies with interstitial nephritis (ISN; $n=5$ ) were also studied. The clinical and pathology parameters pertinent to these specimens have been published previously [13].

\section{RNA sequencing}

RNA was extracted from 1 cubic $\mathrm{mm}$ pieces of formalin fixed paraffin embedded biopsy tissue using the Invitrogen PureLink ${ }^{\mathrm{Tm}}$ FFPE RNA Isolation Kit (Catalog number: K156002), which includes a melting buffer to remove paraffin and a Proteinase $\mathrm{K}$ digestion step. cDNA libraries were constructed from 100 ng total RNA obtained using the Ion Ampliseq Transcriptome Human Gene Expression Kit from Life Technologies (Cat\# A26325) and the manufacturers recommended protocol. Ampliseq Transcriptome analysis was performed by PrimBio Research Institute LLC, Exton, PA, USA, using an Ion Proton sequencer Ion Proton P1 chips, IonXpress barcodes, and Torrrent_Suite 5.0.4 software according to the manufacturer's instructions. Briefly, Library Amp Primers were employed to amplify the purified cDNA library by PCR, and the yield and size of distribution of each library was run on Agilent 2100 Bioanalyzer. Approximately $100 \mathrm{pM}$ of pooled barcoded libraries were used for templating using the Life Technologies Ion Chef Kit. Raw sequence files (fastq) were aligned to the human transcriptome (hg19) reference sequences in StrandNGS software. Gene and transcript annotations were retrieved from the Ensembl database to generate aligned SAM files, which were filtered on read quality $(>15)$, alignment score $(\geq 90)$, match count $(\leq 1)$ and mapping quality $(\geq 25)$. RNA-seq quality control data on these biopsies has been published has been published [14]. RNA purity assessed by the A260/A280 ratio ranged from 1.87 to 2.0. RNA fragments of greater than 200 nucleotides in length comprised greater than $30 \%$ of the total RNA concentration. The mean sequence length in this RNA-Seq data set ranged from 66 to 117 nucleotides. Greater than $98.5 \%$ of the reads aligned to the human transcriptome with accuracy rates of greater than 97\%. Our data has been submitted to the GEO database (GSE120495).

\section{Definition of $\mathrm{HKG} /$ normalization methods}

The term HKG has been conceived to refer to genes responsible for maintenance of fundamental cellular function. These genes are ubiquitously expressed at approximately the same level in all cell-types regardless of developmental stage, physiological condition and presence of external stimuli $[9,15]$. In this study, genes with expression coefficients of variance (CV) corresponding to the 2nd percentile across all 30 samples were assigned to the HKG category as has been suggested in the literature [16]. In a dataset of 47,613 genes this corresponded to 952 genes with the lowest CV. CV was calculated as the ratio of the standard deviation (SD) $\sigma$ to the arithmetical mean $\mu$ of each gene.

Comparison of RNA-seq expression values across multiple samples requires normalization of data. Several 
normalization algorithms have been described in the literature, and we explored nine different methods, namely, library size, TC, UQ, Median, Quantile, RPKM, TPM, TMM and DESeq. Briefly, library size refers to the number of reads that aligned to the human genome. TC refers to transcript counts that remained after removing genes with an expression value of zero in all samples. The UQ scaling factor was calculated as a ratio of the 75th percentile of counts for each sample divided by the mean 75th percentile in all 30 samples [17]. The median scaling factor was obtained in the same manner using the 50th percentile [18]. Quantile normalization was implemented in R software using the "normalizeQuantiles() "function in the EBSeq package (Bioconductor version 3.6). This method sorts the test and reference distributions and proceeds to assign the highest value in latter to the highest value in the former [19]. The RPKM method attempts to normalize first for sequencing depth (per million reads) and then gene length (expressed in kilobases) [20]. TPM normalization proceeds in the reverse order: first, the raw read counts are divided by the length of the gene in kilobases, and then divided by the "per million" scaling factor [21]. TMM normalization was performed using the "calcNormFactors()" function in the edgeR package. The TMM method calculates a scaling factor based on a weighted trimmed mean of log gene expression ratios based on the assumption that most genes are not differentially expressed. Weights are assigned to account for the fact that genes with larger RNA-seq counts have lower variance, and data from both the upper and lower ends are trimmed prior to deriving a scaling factor for the sample library size [22]. Finally, DESeq normalization was implemented in DESeq package by calling the "estimateSizeFactors()" and "sizeFactors()" functions, which are also based on the hypothesis that most genes in the RNA-seq are not differentially expressed [23]. The performance of different normalization methods on our dataset was compared by calculating the bias and variance of genes in each HKG set [24]. The following formulae were used for the calculation of bias and variance, respectively:

$$
\begin{aligned}
& \operatorname{Bias}_{\mathrm{i}}=\sqrt{\frac{1}{n} \sum_{j=1}^{n}\left(\log _{2}\left(\frac{K i j}{\overline{K i}}\right)\right)^{2}} \\
& \text { Variance }_{\mathrm{i}}=\frac{1}{n-1} \sum_{j=1}^{n}\left(\log _{2}\left(\frac{K i j}{\overline{K i}}\right)-\log _{2}\left(\frac{K i j}{\overline{K i}}\right)_{i}\right)^{2}
\end{aligned}
$$

In these formulae, the $\mathrm{K}_{\mathrm{ij}}$ represents the normalized read counts for $i$ th gene from the $j$ th sample, where the $\overline{K i}$. is the mean value of normalized read counts of each gene across 30 samples.

\section{Validation of HKG using published datasets}

It was reasoned that genes classified HKG in this study would have minimal representation in lists of genes known to be differentially expressed in disease states that affect the kidney. Accordingly, we sought overlaps between the HKG dataset, and published gene sets derived from biopsy with T-cell mediated rejection, antibody mediated rejection, polyomavirus nephropathy, and chronic allograft damage [25-28]. Probe sets used to define disease associated genes in these studies were extracted from the NCBI GEO (Gene Expression Omnibus) database, and the corresponding gene and transcript annotations were obtained from the Ensembl database. Overlaps between gene lists of interest were defined by the "Compare" tool available in IPA ${ }^{\circ}$ (Ingenuity Pathway Analysis) software (QIAGEN Biotechnology, Venlo, Netherlands). IPA core analysis was used to define the top-ranked canonical pathways and molecular functions associated with HKGs. A flow diagram of the steps used to identify and validate HKG in this study is presented as Fig. 1.

\section{Results}

\section{Identification of housekeeping genes}

The mean number of reads with a quality score $>$ Q30 obtained from the 30 biopsies ranged from 19 to 28 million, and yielded a total of 57,738 distinct reads that aligned to the hg19 human reference genome. After removing genes with an extracted expression value of zero in all biopsies, 47,613 transcripts remained for further consideration. Nine different HKG sets were created, one for each normalization method. Individual HKG expression accounted for only a small percentage of the total transcription activity in the samples. This is suggested by our calculation of expression ratios that represent mean normalized transcript counts of individual genes expressed as a proportion of the maximal transcript read count in the entire sample set. The numerical value of these expression ratios was less than $<0.05 \%$ for $>70 \%$ of the HKGs. (Table 1). The median coefficient of variation associated with most normalization methods was comparable $(\sim 0.3)$ except for the RPKM and TC methods where it was substantially higher $(0.66 \& 0.43$ respectively) (Fig. 2a). The bias and variance of gene expression measurements was also the highest for these same two normalization methods (Table 1) indicating that the other methods tested by us provide much better data normalization. Similar results were obtained if CVs were calculated for the 42 HKG common to all normalization methods (Fig. 2b).

\section{Validation of housekeeping genes}

By definition, HKG maintain basic cellular functions and their expression does should not change in different 


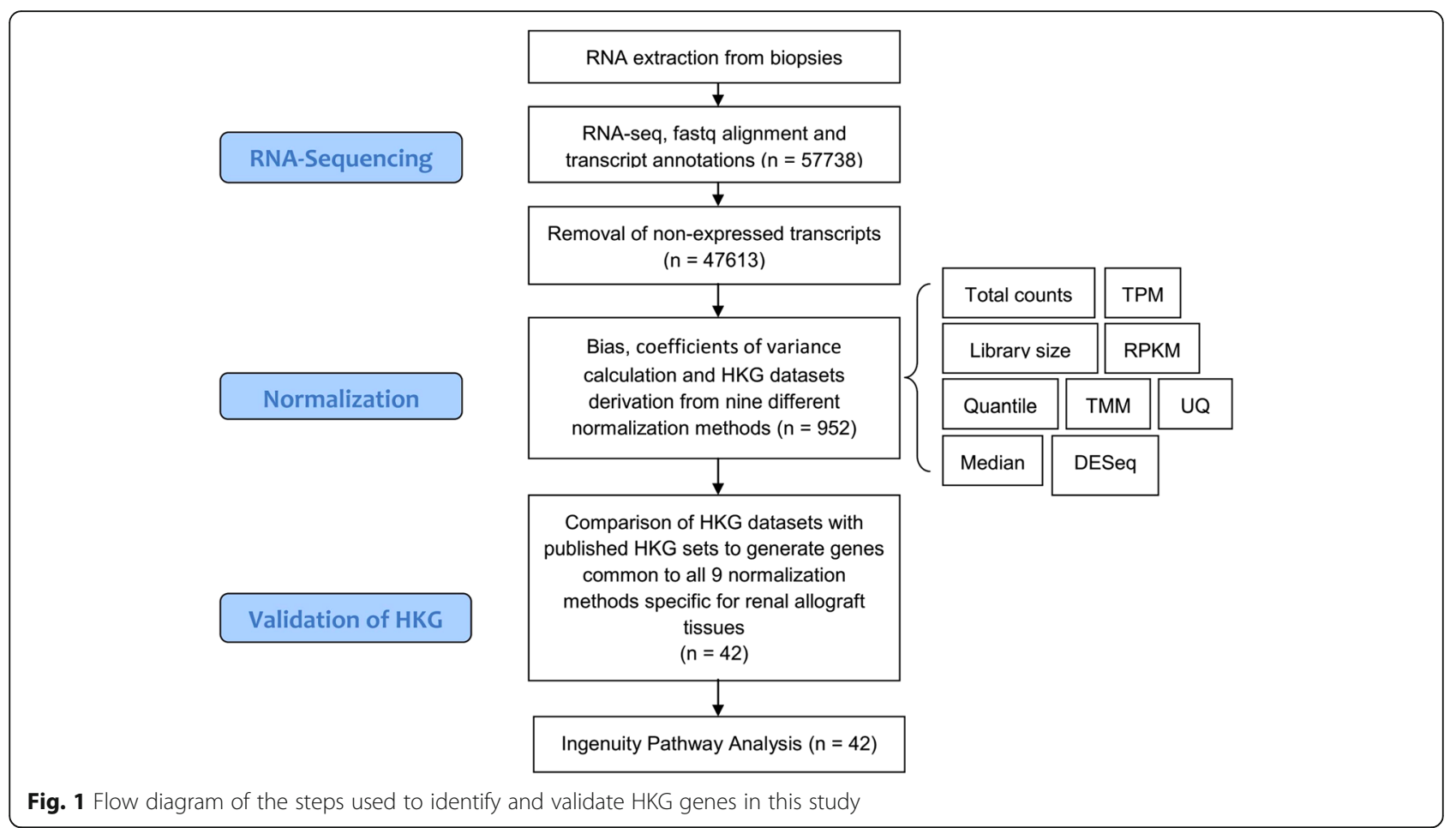

disease states. This prediction was verified using public datasets for 4 common pathologic conditions in the kidney, namely, TCMR, antibody mediated rejection (ABMR), BKVN and chronic allograft injury manifesting as IFTA (Table 2). None of the 952 genes identified as HKG in this study were differentially expressed in human allograft biopsies with TCMR. For the gene lists associated with the remaining biopsy-diagnoses, an overlap of no more than 3 genes was seen with our HKG lists. This is remarkable since Gene Expression Omnibus data used in these comparisons was derived from more than 1000 biopsies.
As an alternate approach to validating the HKG datasets obtained in this study, we compared the constituent genes with HKG lists defined by other investigators using varied technical approaches including expressed sequence tags, DNA microarray, RNA-seq, and massively parallel signature sequencing (Table 3) [29-35]. HKG derived from sequencing based technologies gave the largest number of genes (279 to 656) in common with our own RNA-seq derived gene list. There were fewer (80 to 117) genes shared with microarray technology-based lists. It is apparent that HKG gene identification can be affected by both the normalization

Table 1 Summary of HKG Datasets Defined in This Study Using 9 Different Normalization Methods

\begin{tabular}{llllllllll}
\hline Normalization & \multicolumn{1}{l}{ Expression ratio* } & & & & & Bias $^{* *}$ & Variance $^{* *}$ \\
\cline { 2 - 7 } & $0-0.01(\%)$ & $0.01-0.05(\%)$ & $0.05-0.20(\%)$ & $0.20-0.40(\%)$ & $0.40-0.60(\%)$ & $0.60-0.80(\%)$ & $0.80-1.0(\%)$ & \\
\hline TC & $396(41.60)$ & $473(49.68)$ & $78(8.19)$ & $1(0.11)$ & $1(0.11)$ & $0(0)$ & $3(0.32)$ & 0.74 & 0.55 \\
UQ & $216(22.69)$ & $612(64.29)$ & $115(12.08)$ & $3(0.32)$ & $4(0.42)$ & $1(0.11)$ & $1(0.11)$ & 0.45 & 0.21 \\
Median & $157(16.49)$ & $643(67.54)$ & $142(14.92)$ & $7(0.74)$ & $2(0.21)$ & $0(0)$ & $1(0.11)$ & 0.45 & 0.22 \\
Quantile & $125(13.13)$ & $655(68.80)$ & $161(16.91)$ & $6(0.63)$ & $3(0.32)$ & $1(0.11)$ & $1(0.11)$ & 0.42 & 0.18 \\
TMM & $236(24.79)$ & $599(62.92)$ & $108(11.34)$ & $4(0.42)$ & $4(0.42)$ & $0(0)$ & $1(0.11)$ & 0.47 & 0.23 \\
DESeq & $231(24.26)$ & $610(64.08)$ & $104(10.89)$ & $4(0.42)$ & $2(0.21)$ & $0(0)$ & $1(0.11)$ & 0.43 & 0.19 \\
TPM & $157(16.49)$ & $643(67.54)$ & $142(14.92)$ & $7(0.74)$ & $2(0.21)$ & $0(0)$ & $1(0.11)$ & 0.45 & 0.22 \\
RPKM & $603(63.34)$ & $319(33.51)$ & $26(2.73)$ & $2(0.21)$ & $0(0)$ & $0(0)$ & $2(0.21)$ & 1.04 & 1.03 \\
Lib_size & $202(21.22)$ & $617(64.81)$ & $123(12.92)$ & $7(0.74)$ & $2(0.21)$ & $0(0)$ & $1(0.11)$ & 0.43 & 0.20 \\
\hline
\end{tabular}

Abbreviations: TC total counts, UQ upper quantile, TMM trimmed mean of M-values, DESeq a differential expression package implemented in $\mathrm{R}, T P M$ transcripts per kilobase million, RPKM reads per kilobase per million mapped reads, Lib_size library size

*The expression ratio of each housekeeping gene was calculated by its mean normalized read divided by the maximum reads in its corresponding HKG set

**The bias and variance of each normalization method was calculated by the formulae 


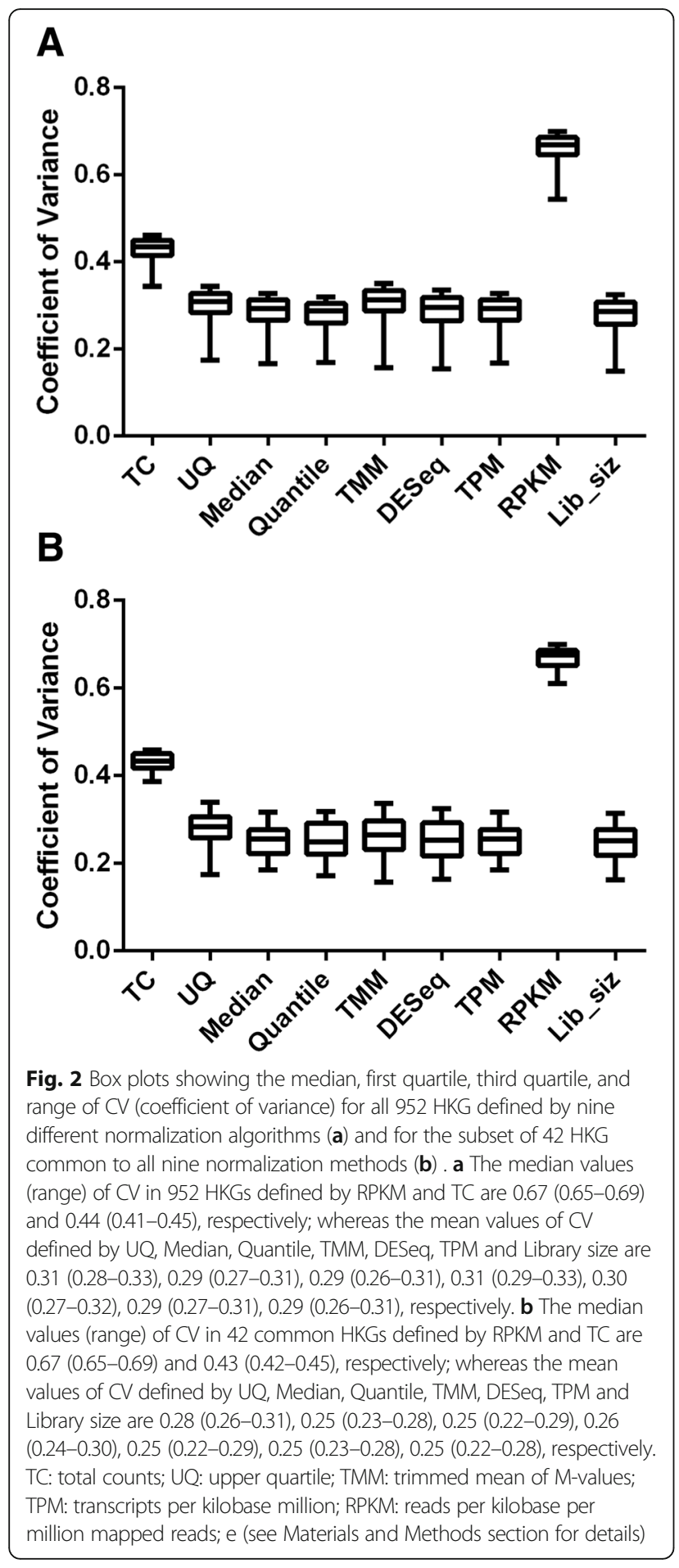

method used as well as the technology applied to measure gene expression. The type of tissue analyzed is also an important variable. Whereas all our samples represent the allograft kidney, the aforementioned prior studies included multiple organs in their analysis. Thus, different HKG gene sets can be equally valid depending on the clinical setting and sample set being investigated.

\section{Pathway analyses}

Ingenuity pathway analysis was performed on 42 genes common to 9 HKG sets derived from different normalization methods. The Entrez gene names and molecular functions of these genes are listed in Table 4. The majority are involved in chromatin, core promoter, DNA, mRNA, protein, or ATP binding, while others represent ubiquitous enzymes belonging to the protein kinase, phosphatase, protease, ligase, ATPase or GTPase family. Physiologic functions mediated by these housekeeping genes included regulation of the cell cycle, cell to cell signaling, post-translational modifications, cell morphology, cell movement, molecular transport, and lipid or nucleic acid metabolism (Figs. 3 and 4, Table 5). The top 4 canonical pathways identified all involved de novo or salvage pathways of pyrimidine biosynthesis, including pyrimidine ribonucleotides interconversion, pyrimidine ribonucleotides de novo biosynthesis, and pyrimidine deoxyribonucleotides de novo biosynthesis. Notably, less than $5 \%$ of the genes in these pathways met the criterion for being classified as a housekeeping gene. The majority of the remaining canonical pathways were related to protein signaling mediated by the protein kinase A, p38 MAPK, RhoA, CREB, ERK/MAPK, Eif4, p70S6K, IL-12, glucocorticoid receptor, estrogen receptor, or progesterone receptor pathways.

\section{Discussion}

The primary purpose of this study was to identify HKG appropriate for analyzing RNA-seq data derived from human renal allograft biopsies. It is expected that RNA-seq technology will be increasingly applied to discover molecular signatures relevant to the diagnosis, prognosis and therapy of diseases that commonly afflict kidney transplant recipients. The work performed has identified 9 HKG sets using different normalization methods and the question arises which gene set is most applicable to the analysis of gene expression data derived from renal allograft biopsies. Zyprych-Walczak et al. [36] analyzed transcripts from mammary epithelial cell lines, B-cells, and blood or bone marrow samples from patients with acute myeloid leukemia. They compared six normalization algorithms with respect to sensitivity, specificity, classification errors, and generation of diagnostic plots, and found that bias and variance were appropriate indices to compare the performance of different normalization methods. Application of this principle to our data indicates normalization using only the TC or RPKM methods is not advisable. The other normalization methods give essentially comparable results, although the quantiles method is nominally better than all the others that were tested. The basic idea behind RPKM is to normalize the reads first by total reads and then by gene length. Previous studies have confirmed the 
Table 2 Overlaps $^{\mathrm{a}}$ Between Gene Expression Datasets Derived from Diseased Allograft Kidney \& HKG Defined in This Study

\begin{tabular}{|c|c|c|c|c|c|c|c|c|c|c|c|c|}
\hline \multirow[t]{2}{*}{ Reference } & \multirow[t]{2}{*}{ \#Biopsies } & \multirow{2}{*}{$\begin{array}{l}\text { \#of DE } \\
\text { transcripts }\end{array}$} & \multirow{2}{*}{$\begin{array}{l}\text { Biopsy } \\
\text { Diagnosis }\end{array}$} & \multicolumn{9}{|c|}{ Normalization method Used to Define HKG } \\
\hline & & & & TC (\%) & UQ (\%) & Median (\%) & Quantile (\%) & TMM (\%) & DESeq (\%) & TPM (\%) & RPKM (\%) & Lib_siz (\%) \\
\hline [25] & 703 & 453 & $A B M R$ & $2(0.40)$ & $2(0.44)$ & $2(0.44)$ & $2(0.44)$ & $1(0.22)$ & $2(0.44)$ & $2(0.44)$ & $8(1.77)$ & $1(0.22)$ \\
\hline [26] & 708 & 82 & TCMR & $0(0)$ & $0(0)$ & $0(0)$ & $0(0)$ & $0(0)$ & $0(0)$ & $0(0)$ & $0(0)$ & $0(0)$ \\
\hline [27] & 168 & 206 & BKVN & $3(1.46)$ & $5(2.43)$ & $3(1.46)$ & $3(1.46)$ & $3(1.46)$ & $3(1.46)$ & $3(1.46)$ & $3(1.46)$ & $3(1.46)$ \\
\hline [28] & 204 & 82 & $\begin{array}{l}\text { Chronic } \\
\text { allograft } \\
\text { damage }\end{array}$ & $1(1.22)$ & $1(1.22)$ & $2(2.44)$ & $2(2.44)$ & $1(1.22)$ & $1(1.22)$ & $2(2.44)$ & $1(1.22)$ & $2(2.44)$ \\
\hline
\end{tabular}

Abbreviations: ABMR antibody mediated rejection, DE differentially expressed, TCMR T-cell mediated rejection, BKVN polyomavirus nephropathy, For other abbreviations, see legend to Table 1

${ }^{a}$ The total number of overlapping genes with the specified datasets is enumerated

suboptimal performance of this method [17, 37, 38]. Interestingly, better performance was seen with TPM which differs from RPKM only in that normalization for gene length precedes correction for total reads. This reversal in the order of operations led to relatively uniform transcript counts in all 30 biopsies. However, in one prior study both TC and RPKM led to unsatisfactory results [39]. Two prior investigations noted that the quantile method is associated with lower variance in observed gene expression data, but there is a tradeoff that results in the introduction of some bias $[19,40]$. Another study reported that DESeq method is the best for the normalization [39].

Our assessment of the published literature is that no single normalization method can be universally recommended for all data sets. HKG lists vary depending on study design, tissues analyzed, sequencing technology, normalization methods, as well as criteria and tools for housekeeping gene selection [41, 42]. Data distribution and analytic plans can influence the choice of normalization method: e.g. if most genes have low expression, upper quantile rather than median normalization should be preferred. On the other hand, if differential expression is to be performed by the DESeq program, the normalization algorithm incorporated in the software can work directly with unnormalized RNA-seq counts. Finally, we suggest that when working with renal allograft biopsies, the problem of choosing the right HKG set can be circumvented by using the list of 42 genes (Table 4) that is common to gene sets derived by 9 different algorithms.

Table 3 Comparison of Published housekeeping genes with HKG Datasets Defined in This Study

\begin{tabular}{|c|c|c|c|c|c|c|c|c|c|c|c|c|c|c|}
\hline \multirow[t]{2}{*}{ Study } & \multirow[t]{2}{*}{ \#samples } & \multirow[t]{2}{*}{$\# H K G$} & \multirow{2}{*}{$\begin{array}{l}\text { \#Tissues/cells } \\
\text { studied }\end{array}$} & \multirow{2}{*}{ Technique } & \multirow{2}{*}{$\begin{array}{l}\text { Normalization } \\
\text { method }\end{array}$} & \multicolumn{9}{|c|}{ Housekeeping Gene Set Stratified by Normalization Method ${ }^{a}$} \\
\hline & & & & & & TC (\%) & $\begin{array}{l}\text { UQ } \\
(\%)\end{array}$ & $\begin{array}{l}\text { Median } \\
(\%)\end{array}$ & $\begin{array}{l}\text { Quantile } \\
(\%)\end{array}$ & $\begin{array}{l}\text { TMM } \\
(\%)\end{array}$ & $\begin{array}{l}\text { DESeq } \\
(\%)\end{array}$ & $\begin{array}{l}\text { TPM } \\
(\%)\end{array}$ & $\begin{array}{l}\text { RPKM } \\
(\%)\end{array}$ & $\begin{array}{l}\text { Lib_siz } \\
(\%)\end{array}$ \\
\hline (4) & 142 & 1789 & 79 & Microarray & $N A^{b}$ & $\begin{array}{l}94 \\
(5.25)\end{array}$ & $\begin{array}{l}91 \\
(5.09)\end{array}$ & $\begin{array}{l}115 \\
(6.43)\end{array}$ & $\begin{array}{l}111 \\
(6.20)\end{array}$ & $\begin{array}{l}92 \\
(5.14)\end{array}$ & $\begin{array}{l}89 \\
(4.97)\end{array}$ & $\begin{array}{l}115 \\
(6.43)\end{array}$ & $\begin{array}{l}76 \\
(4.25)\end{array}$ & $\begin{array}{l}96 \\
(5.37)\end{array}$ \\
\hline (5) & 18 & 2403 & 18 & Microarray & NA & $\begin{array}{l}110 \\
(4.58)\end{array}$ & $\begin{array}{l}145 \\
(6.03)\end{array}$ & $\begin{array}{l}158 \\
(6.58)\end{array}$ & $\begin{array}{l}161 \\
(6.70)\end{array}$ & $\begin{array}{l}132 \\
(5.49)\end{array}$ & $\begin{array}{l}124 \\
(5.16)\end{array}$ & $\begin{array}{l}158 \\
(6.58)\end{array}$ & $\begin{array}{l}103 \\
(4.29)\end{array}$ & $\begin{array}{l}133 \\
(5.53)\end{array}$ \\
\hline (6) & 42 & 1522 & 42 & Microarray & NA & $\begin{array}{l}89 \\
(5.84)\end{array}$ & $\begin{array}{l}112 \\
(7.36)\end{array}$ & $\begin{array}{l}117 \\
(7.69)\end{array}$ & $\begin{array}{l}115 \\
(7.56)\end{array}$ & $\begin{array}{l}87 \\
(5.72)\end{array}$ & $\begin{array}{l}88 \\
(5.78)\end{array}$ & $\begin{array}{l}117 \\
(7.69)\end{array}$ & $\begin{array}{l}80 \\
(5.26)\end{array}$ & $\begin{array}{l}92 \\
(6.04)\end{array}$ \\
\hline (6) & NA & 15,050 & 32 & sequencing_MPSS & TPM & $\begin{array}{l}516 \\
(3.43)\end{array}$ & $\begin{array}{l}578 \\
(3.84)\end{array}$ & $\begin{array}{l}566 \\
(3.76)\end{array}$ & $\begin{array}{l}581 \\
(3.86)\end{array}$ & $\begin{array}{l}550 \\
(3.65)\end{array}$ & $\begin{array}{l}559 \\
(3.71)\end{array}$ & $\begin{array}{l}566 \\
(3.76)\end{array}$ & $\begin{array}{l}489 \\
(3.25)\end{array}$ & $\begin{array}{l}559 \\
(3.71)\end{array}$ \\
\hline$(7)$ & 2502 & 6909 & 18 & Sequencing_EST & NA & $\begin{array}{l}398 \\
(5.76)\end{array}$ & $\begin{array}{l}542 \\
(7.84)\end{array}$ & $\begin{array}{l}533 \\
(7.71)\end{array}$ & $\begin{array}{l}551 \\
(7.98)\end{array}$ & $\begin{array}{l}463 \\
(6.70)\end{array}$ & $\begin{array}{l}458 \\
(6.63)\end{array}$ & $\begin{array}{l}533 \\
(7.71)\end{array}$ & $\begin{array}{l}369 \\
(5.34)\end{array}$ & $\begin{array}{l}471 \\
(6.82)\end{array}$ \\
\hline (8) & NA & 12,714 & 19 & sequencing_EST & NA & $\begin{array}{l}583 \\
(4.59)\end{array}$ & $\begin{array}{l}627 \\
(4.93)\end{array}$ & $\begin{array}{l}642 \\
(5.05)\end{array}$ & $\begin{array}{l}656 \\
(5.16)\end{array}$ & $\begin{array}{l}610 \\
(4.80)\end{array}$ & $\begin{array}{l}620 \\
(4.88)\end{array}$ & $\begin{array}{l}642 \\
(5.05)\end{array}$ & $\begin{array}{l}546 \\
(4.29)\end{array}$ & $\begin{array}{l}628 \\
(4.94)\end{array}$ \\
\hline (9) & NA & 7896 & 32 & RNA-Seq & RPKM & $\begin{array}{l}514 \\
(6.51)\end{array}$ & $\begin{array}{l}628 \\
(7.95)\end{array}$ & $\begin{array}{l}654 \\
(8.28)\end{array}$ & $\begin{array}{l}656 \\
(8.31)\end{array}$ & $\begin{array}{l}601 \\
(7.61)\end{array}$ & $\begin{array}{l}594 \\
(7.52)\end{array}$ & $\begin{array}{l}654 \\
(8.28)\end{array}$ & $\begin{array}{l}441 \\
(5.59)\end{array}$ & $\begin{array}{l}615 \\
(7.79)\end{array}$ \\
\hline (10) & 16 & 3804 & 16 & RNA-Seq & RPKM & $\begin{array}{l}279 \\
(7.33)\end{array}$ & $\begin{array}{l}361 \\
(9.49)\end{array}$ & $\begin{array}{l}372 \\
(9.78)\end{array}$ & $\begin{array}{l}379 \\
(9.96)\end{array}$ & $\begin{array}{l}317 \\
(8.33)\end{array}$ & $\begin{array}{l}315 \\
(8.28)\end{array}$ & $\begin{array}{l}372 \\
(9.78)\end{array}$ & $\begin{array}{l}212 \\
(5.57)\end{array}$ & $\begin{array}{l}329 \\
(8.64)\end{array}$ \\
\hline
\end{tabular}

Abbreviations: EST expressed sequence tags, HKG housekeeping genes, MPSS Massively parallel signature sequencing, $A B M R$ antibody mediated rejection, DE differentially expressed, TCMR T-cell mediated rejection, PVAN polyomavirus nephropathy, NA not available; for other abbreviations, see legend to Table 1

${ }^{a}$ The total number (\%) of overlapping genes with the specified datasets is enumerated. Percentage calculations are based on the total number of HKG in column 3

${ }^{b}$ The normalization methods in these references were not mentioned, but the most common method used for microarray data is

Quantile normalization 
Table 4 Housekeeping Genes $(n=42)$ Common to All Normalization Methods

\begin{tabular}{|c|c|c|c|}
\hline Entrez Gene ID & Transcripts & Entrez Gene Name & Molecular function \\
\hline 51,433 & ANAPC5 & anaphase promoting complex subunit 5 & protein phosphatase binding \\
\hline 25,906 & ANAPC15 & anaphase promoting complex subunit 15 & anaphase-promoting complex \\
\hline 10,620 & ARID3B & AT-rich interaction domain 3B & transcription regulator \\
\hline 285,598 & ARL10 & ADP ribosylation factor like GTPase 10 & small GTPase mediated signal transduction \\
\hline 6311 & ATXN2 & ataxin 2 & epidermal growth factor receptor binding \\
\hline 57,020 & C16orf62 & chromosome 16 open reading frame 62 & protein binding \\
\hline 132,200 & C3orf49 & chromosome 3 open reading frame 49 & unknown \\
\hline 55,749 & CCAR1 & cell division cycle and apoptosis regulator 1 & core promoter binding \\
\hline 202,243 & CCDC125 & coiled-coil domain containing 125 & regulation of cell motility \\
\hline 60,492 & CCDC90B & coiled-coil domain containing 90B & protein binding \\
\hline 55,743 & CHFR & checkpoint with forkhead and ring finger domains & E3 ubiquitin-protein ligase \\
\hline 207,063 & DHRSX & dehydrogenase/reductase X-linked & oxidoreductase activity \\
\hline 83,786 & FRMD8 & FERM domain containing 8 & protein binding \\
\hline 26,088 & GGA1 & $\begin{array}{l}\text { golgi associated, gamma adaptin ear containing, ARF } \\
\text { binding protein } 1\end{array}$ & cellular protein metabolic process \\
\hline 26,091 & HERC4 & $\begin{array}{l}\text { HECT and RLD domain containing E3 ubiquitin protein } \\
\text { ligase } 4\end{array}$ & transferase activity; ubiquitin-protein ligase activity \\
\hline 8569 & MKNK1 & MAP kinase interacting serine/threonine kinase 1 & $\begin{array}{l}\text { ATP binding; calcium-dependent protein serine/threo } \\
\text { nine kinase activity }\end{array}$ \\
\hline 4678 & NASP & nuclear autoantigenic sperm protein & histone binding; Hsp90 protein binding; \\
\hline 4833 & NME4 & NME/NM23 nucleoside diphosphate kinase 4 & ubiquitous enzymes \\
\hline 55,611 & OTUB1 & OTU deubiquitinase, ubiquitin aldehyde binding 1 & NEDD8-specific protease activity \\
\hline $11,243 \mid 100,527,963$ & PMF1/PMF1-BGLAP & polyamine modulated factor 1 & leucine zipper domain binding \\
\hline 5431 & POLR2B & RNA polymerase II subunit B & chromatin binding \\
\hline 11,128 & POLR3A & RNA polymerase III subunit A & chromatin binding \\
\hline 84,197 & POMK & protein-O-mannose kinase & ATP binding; carbohydrate kinase activity \\
\hline 379,025 & PSMA3-AS1 & PSMA3 antisense RNA 1 & unknown \\
\hline 5784 & PTPN14 & protein tyrosine phosphatase, non-receptor type 14 & hydrolase activity; phosphatase activity \\
\hline 51,735 & RAPGEF6 & Rap guanine nucleotide exchange factor 6 & GTP-dependent protein binding \\
\hline 5966 & REL & REL proto-oncogene, NF-kB subunit & chromatin binding; DNA binding \\
\hline 8568 & RRP1 & ribosomal RNA processing 1 & RNA binding \\
\hline 146,923 & RUNDC1 & RUN domain containing 1 & GTPase activator activity; Rab GTPase binding \\
\hline 55,095 & SAMD4B & sterile alpha motif domain containing $4 \mathrm{~B}$ & mRNA binding; \\
\hline 22,950 & SLC4A1AP & solute carrier family 4 member 1 adaptor protein & mRNA binding; protein binding \\
\hline 7871 & SLMAP & sarcolemma associated protein & protein binding \\
\hline 50,485 & SMARCAL1 & $\begin{array}{l}\text { SWI/SNF related, matrix associated, actin dependent } \\
\text { regulator of chromatin, subfamily a like } 1\end{array}$ & ATP binding; DNA-dependent ATPase activity \\
\hline 9342 & SNAP29 & synaptosome associated protein 29 & protein binding; SNAP receptor activity \\
\hline 23,020 & SNRNP200 & small nuclear ribonucleoprotein U5 subunit 200 & ATP binding; ATP-dependent helicase activity \\
\hline 6827 & SUPT4H1 & SPT4 homolog, DSIF elongation factor subunit & metal ion binding; protein binding \\
\hline 25,771 & TBC1D22A & TBC1 domain family member 22A & 14-3-3 protein binding; GTPase activator activity \\
\hline 440,944 & THUMPD3-AS1 & THUMPD3 antisense RNA 1 & unknown \\
\hline $100,506,779$ & TSPOAP1-AS1 & TSPOAP1 antisense RNA 1 & unknown \\
\hline 10,844 & TUBGCP2 & tubulin gamma complex associated protein 2 & gamma-tubulin binding \\
\hline 23,038 & WDTC1 & WD and tetratricopeptide repeats 1 & enzyme inhibitor activity \\
\hline 27,300 & ZNF544 & zinc finger protein 544 & DNA binding; metal ion binding \\
\hline
\end{tabular}




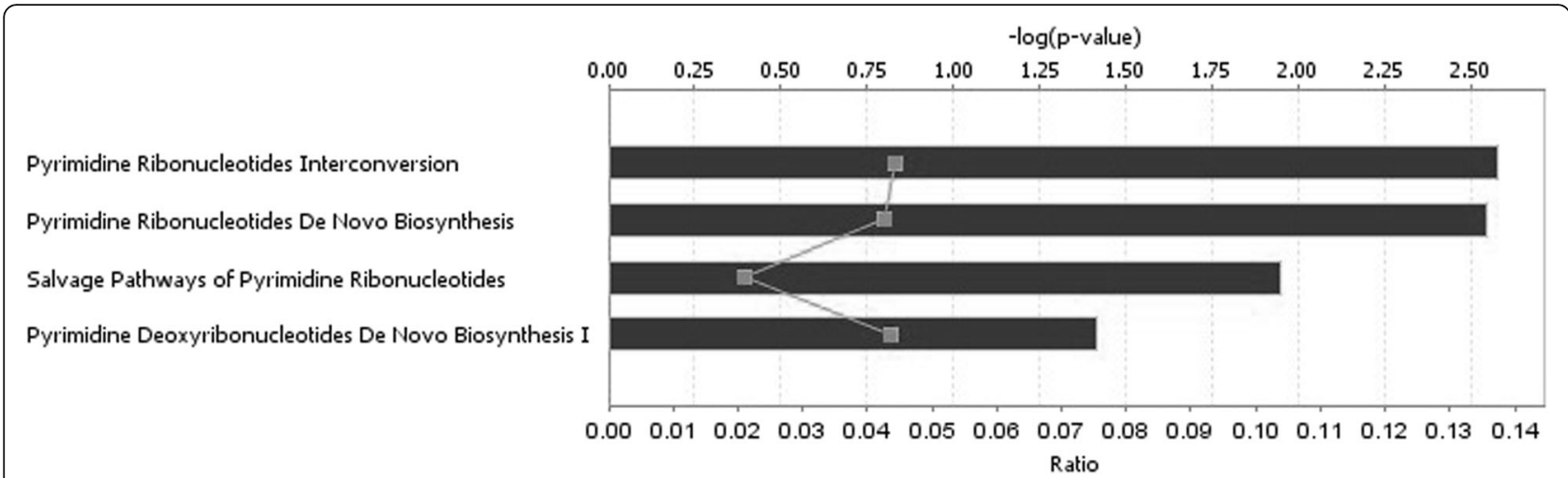

Fig. 3 Canonical pathways identified by IPA core analysis as over-represented amongst 42 HKG common to 9 different data normalization methods. Pathways meeting statistical confidence thresholds preset in IPA are identified on the Y-axis (- $\log _{10} p=1.3$, right-tailed Fisher's exact test). The lower $X$-axis and the line diagram display the proportion of total genes in the specified pathway that meet the cutoff criteria for identification

The HKG proposed in this study have been validated with reference to publicly available external gene expression datasets obtained on an independent platform, namely, the Affymetrix DNA microarray analysis system. These latter datasets were derived from kidney transplant biopsies with TCMR, ABMR, BKVN or i-IFTA. A second observation that validates our HKG gene lists is that these share up to 656 genes with other RNA-seq derived gene lists in the literature. Finally, our IPA analysis is consistent with the proposed housekeeping function of these genes, and is concordant with putative cellular and biologic functions of other HKG reported in the literature. These reported functions include RNA processing, RNA splicing, DNA repair and mRNA metabolic processes [43], cell morphology and signaling, defense/ apoptosis, ribosomal protein signaling/communication, structure/motility [44, 45], and biogenesis of nucleotides/amino acids and protein localization [35]. It is to be noted that some genes such as GAPHD and beta actin (ACTB), which are widely used in biological experiments as housekeeping controls, do not appear in our HKG set [46-48]. Likewise, our gene list does not include 8 genes that have been suggested to be suitable as a reference set for studies of the non-transplanted kidney [49].

\section{Conclusion}

In summary, we have developed several different HKG gene lists applicable to RNA-seq data derived from for human allograft kidney biopsies and processed by a variety of normalization methods. We have also assembled a universal set of 42 HKG that can be used without regard to the actual normalization

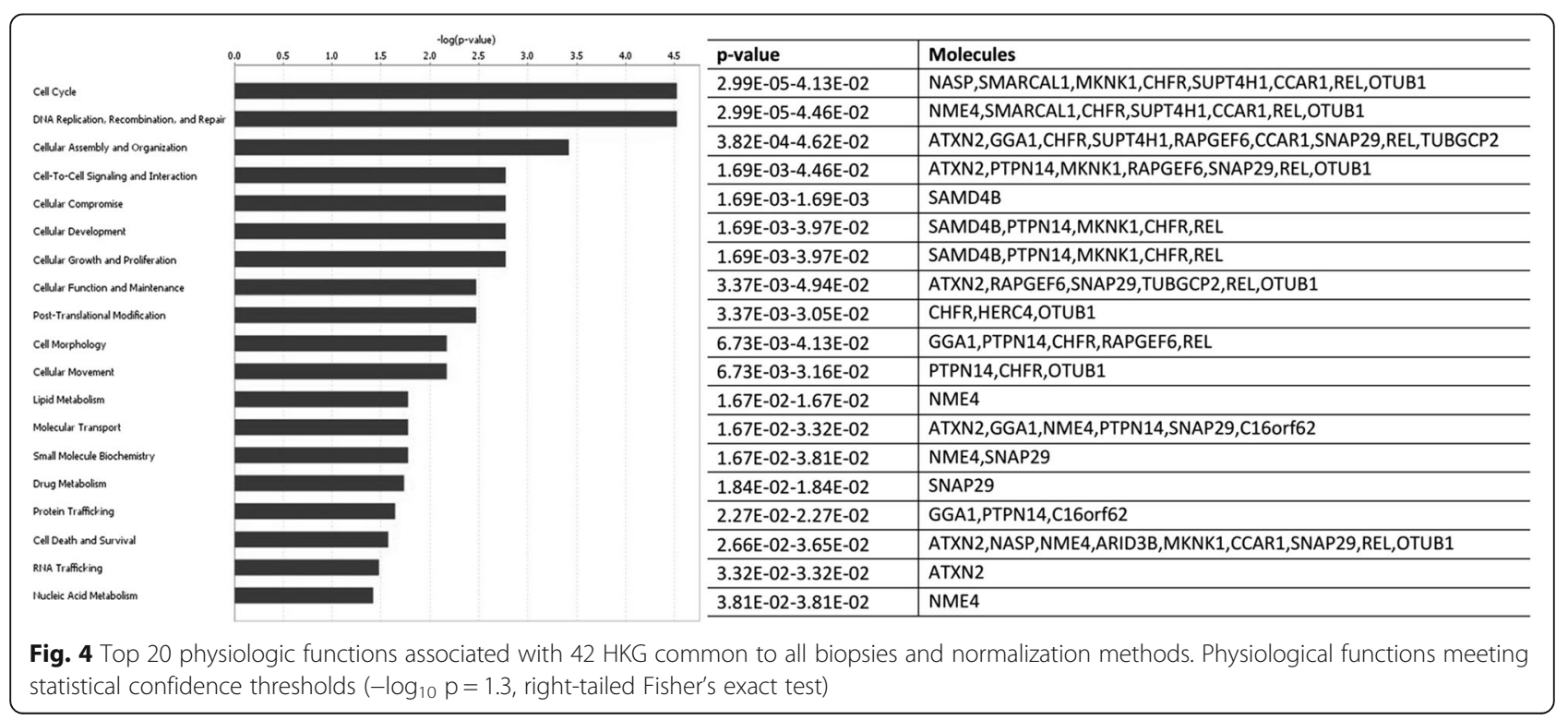


Table 5 Canonical Pathways identified by IPA software for 42 Housekeeping Genes Common to All Normalization Methods

\begin{tabular}{|c|c|c|c|}
\hline Ingenuity Canonical Pathways & $-\log (p$-value $)$ & Ratio & Molecules \\
\hline Pyrimidine Ribonucleotides Interconversion & 2.58 & 0.0444 & NME4,SMARCAL1 \\
\hline Pyrimidine Ribonucleotides De Novo Biosynthesis & 2.55 & 0.0426 & NME4,SMARCAL1 \\
\hline Salvage Pathways of Pyrimidine Ribonucleotides & 1.95 & 0.0211 & NME4,POMK \\
\hline Pyrimidine Deoxyribonucleotides De Novo Biosynthesis I & 1.42 & 0.0435 & NME4 \\
\hline Nucleotide Excision Repair Pathway & 1.24 & 0.0286 & POLR2B \\
\hline Assembly of RNA Polymerase II Complex & 1.09 & 0.02 & POLR2B \\
\hline Pyridoxal 5'-phosphate Salvage Pathway & 0.983 & 0.0154 & POMK \\
\hline Mitotic Roles of Polo-Like Kinase & 0.977 & 0.0152 & ANAPC5 \\
\hline Protein Kinase A Signaling & 0.836 & 0.005 & PTPN14,ANAPC5 \\
\hline Androgen Signaling & 0.767 & 0.00901 & POLR2B \\
\hline p38 MAPK Signaling & 0.736 & 0.00833 & MKNK1 \\
\hline RhoA Signaling & 0.723 & 0.00806 & RAPGEF6 \\
\hline Estrogen Receptor Signaling & 0.711 & 0.00781 & POLR2B \\
\hline Hereditary Breast Cancer Signaling & 0.665 & 0.00694 & POLR2B \\
\hline IL-12 Signaling and Production in Macrophages & 0.66 & 0.00685 & REL \\
\hline Regulation of elF4 and p70S6K Signaling & 0.632 & 0.00637 & MKNK1 \\
\hline CREB Signaling in Neurons & 0.568 & 0.00538 & POLR2B \\
\hline RAR Activation & 0.56 & 0.00526 & REL \\
\hline ERK/MAPK Signaling & 0.541 & 0.005 & MKNK1 \\
\hline Systemic Lupus Erythematosus Signaling & 0.499 & 0.00444 & SNRNP200 \\
\hline Huntington's Disease Signaling & 0.461 & 0.004 & POLR2B \\
\hline Protein Ubiquitination Pathway & 0.441 & 0.00377 & ANAPC5 \\
\hline Glucocorticoid Receptor Signaling & 0.358 & 0.00295 & POLR2B \\
\hline Axonal Guidance Signaling & 0.27 & 0.00221 & MKNK1 \\
\hline
\end{tabular}

procedure used. The study is limited by the small number of biopsies studied and use of formalin fixed paraffin embedded tissue, which may not be optimal to detect genes expressed at low abundance. However, low abundance genes have high variance and are not good candidates for the HKG designation. Importantly, the general bioinformatics approach that we have outlined is applicable to define HKG for RNAseq datasets of any size and RNA quality for transplantation of all organs. Appropriate normalization of samples with a comprehensive set of HKG provides a mechanism to correct for batch effects, which can be a significant obstacle in the implementation of RNAseq as a monitoring tool in the transplant clinic.

\section{Abbreviations}

ABMR: Antibody mediated rejection; ACTB: Beta actin; ATI: Acute tubular injury; CV: Coefficients of variance; GAPDH: Glyceraldehyde-3-phosphate dehydrogenase; GEO: Gene Expression Omnibus; HKG: Housekeeping genes; IFTA: Interstitial fibrosis and tubular atrophy; IPA: Ingenuity Pathway Analysis; ISN: Interstitial nephritis; RNA-seq: RNA-sequencing; RPKM: Reads per kilobase million; STA: Stable allograft function; TC: Total counts; TCMR: T cell-mediated rejection; TMM: Trimmed mean of $\mathrm{M}$-values; TPM: Transcripts per kilobase million; UQ: Upper quartile

\section{Acknowledgments}

We are thankful for travel support to ZJ Wang provided by The International Exchange and Cooperation Project of Graduate Education at Nanjing Medical University, and to laboratory facilities provided to PR by The Division of

Transplantation Pathology, Department of Pathology, University of Pittsburgh.

\section{Authors' contributions}

ZJW: Data analysis and manuscript preparation; ZLL: Data interpretation; LP: Data interpretation; GZ: Study design and data analysis; PR: Study design, manuscript preparation and funding. All authors read and approved the final version of the manuscript.

\section{Funding}

None.

\section{Availability of data and materials}

The datasets supporting the conclusions of this article are available in the Gene Expression Omnibus (GEO) database (GSE120495, https://www.ncbi. nlm.nih.gov/geo/).

Ethics approval and consent to participate

The entire study was performed on identified tissues from the tissue bank by an honest broker mechanism. The protocol for acquiring tissues was reviewed and approved by the University of Pittsburgh Institutional Review Board (IRB protocol \# 10110393).

Consent for publication

Not applicable. 


\section{Competing interests}

The authors declare that they have no competing interests.

\section{Author details}

'Department of Urology, The First Affiliated Hospital of Nanjing Medical University, Nanjing 210029, China. ${ }^{2}$ Department of Pathology, The First Affiliated Hospital of Guangxi Medical University, Nanning 530021, China. ${ }^{3}$ Department of Nephrology, The First Affiliated Hospital of Guangxi Medica University, Nanning 530021, China. ${ }^{4}$ Department of Pathology, University of Pittsburgh Medical Center, E737 UPMC-Montefiore Hospital, 3459 Fifth Ave, Pittsburgh, PA 15213, USA.

Received: 14 October 2018 Accepted: 24 May 2019 Published online: 17 June 2019

\section{References}

1. Lau D, Bobe AM, Khan AA. RNA sequencing of the tumor microenvironment in precision Cancer immunotherapy. Trends Cancer. 2019;5(3):149-56

2. Maekawa S, Wang PC, Chen SC. Comparative study of immune reaction against bacterial infection from transcriptome analysis. Front Immunol. 2019; 10:153.

3. Goovaerts T, Steyaert S, Vandenbussche CA, Galle J, Thas O, Van Criekinge W, et al. A comprehensive overview of genomic imprinting in breast and its deregulation in cancer. Nat Commun. 2018;9(1):4120.

4. Rogawski DS, Vitanza NA, Gauthier AC, Ramaswamy V, Koschmann C. Integrating RNA sequencing into neuro-oncology practice. Transl Res. 2017; 189:93-104.

5. Arzalluz-Luque A, Devailly G, Mantsoki A, Joshi A. Delineating biological and technical variance in single cell expression data. Int J Biochem Cell Biol. 2017;90:161-6.

6. Scarpato M, Esposito R, Evangelista D, Aprile M, Ambrosio MR, Angelini C, et al. AnaLysis of expression on human chromosome 21, ALE-HSA21: a pilot integrated web resource. Database (Oxford). 2014;2014:bau009.

7. Papalexi E, Satija R. Single-cell RNA sequencing to explore immune cell heterogeneity. Nat Rev Immunol. 2018;18(1):35-45.

8. Marinov GK. On the design and prospects of direct RNA sequencing. Brief Funct Genomics. 2017;16(6):326-35.

9. Chang CW, Cheng WC, Chen CR, Shu WY, Tsai ML, Huang CL, et al. Identification of human housekeeping genes and tissue-selective genes by microarray meta-analysis. PLoS One. 2011;6(7):e22859.

10. Suhre K, Schwartz JE, Sharma VK, Chen Q, Lee JR, Muthukumar T, et al. Urine metabolite profiles predictive of human kidney allograft status. J Am Soc of Nephrol. 2016;27(2):626-36

11. Zhao C, Xu Z, Wang Z, Suo C, Tao J, Han Z, et al. Role of tumor necrosis factor-alpha in epithelial-to-mesenchymal transition in transplanted kidney cells in recipients with chronic allograft dysfunction. Gene. 2018;642:483-90.

12. Jella KK, Yu L, Yue Q, Friedman D, Duke BJ, Alli AA. Exosomal GAPDH from proximal tubule cells regulate ENaC activity. PLoS One. 2016;11(11): e0165763.

13. Pan L, Lyu Z, Adam B, Zeng G, Wang Z, Huang Y, et al. Polyomavirus BK nephropathy-associated transcriptomic signatures: a critical reevaluation. Transplant Direct. 2018;4(2):e339.

14. Liu P, Tseng G, Wang Z, Huang Y, Randhawa P. Diagnosis of T-cell-mediated kidney rejection in formalin-fixed, paraffin-embedded tissues using RNASeq-based machine learning algorithms. Hum Pathol. 2019;84:283-90.

15. Chen CM, Lu YL, Sio CP, Wu GC, Tzou WS, Pai TW. Gene ontology based housekeeping gene selection for RNA-seq normalization. Methods. 2014 67(3):354-63.

16. Zeng J, Liu S, Zhao Y, Tan X, Aljohi HA, Liu W, et al. Identification and analysis of house-keeping and tissue-specific genes based on RNA-seq data sets across 15 mouse tissues. Gene. 2016:576(1 Pt 3):560-70.

17. Bullard JH, Purdom E, Hansen KD, Dudoit S. Evaluation of statistical methods for normalization and differential expression in mRNA-Seq experiments. BMC Bioinformatics. 2010;11:94

18. Anders $S$, Huber W. Differential expression analysis for sequence count data. Genome Biol. 2010;11(10):R106.

19. Bolstad BM, Irizarry RA, Astrand M, Speed TP. A comparison of normalization methods for high density oligonucleotide array data based on variance and bias. Bioinformatics. 2003;19(2):185-93.
20. Torres-Oliva M, Almudi I, McGregor AP, Posnien N. A robust (re-)annotation approach to generate unbiased mapping references for RNA-seq-based analyses of differential expression across closely related species. BMC Genomics. 2016;17:392.

21. Wagner GP, Kin K, Lynch VJ. A model based criterion for gene expression calls using RNA-seq data. Theory Biosci. 2013;132(3):159-64.

22. Maza E. In Papyro comparison of TMM (edgeR), RLE (DESeq2), and MRN normalization methods for a simple two-conditions-without-replicates RNASeq experimental design. Front Genet. 2016;7:164.

23. Li P, Piao Y, Shon HS, Ryu KH. Comparing the normalization methods for the differential analysis of Illumina high-throughput RNA-Seq data. BMC Bioinformatics. 2015;16:347.

24. Uszczynska B, Zyprych-Walczak J, Handschuh L, Szabelska A, Kazmierczak M, Woronowicz W, et al. Analysis of boutique arrays: a universal method for the selection of the optimal data normalization procedure. Int J Mol Med. 2013;32(3):668-84

25. Halloran PF, Famulski KS, Chang JA. Probabilistic approach to histologic diagnosis of antibody-mediated rejection in kidney transplant biopsies. Am J Transplant Off J Am Soc Transplant Am Soc Transplant Surg. 2017;17(1): 129-39.

26. Halloran PF, Pereira AB, Chang J, Matas A, Picton M, De Freitas D, et al. Potential impact of microarray diagnosis of T cell-mediated rejection in kidney transplants: the INTERCOM study. Am J Transplant Off J Am Soc Transplant Am Soc Transplant Surg. 2013;13(9):2352-63.

27. Sigdel TK, Bestard O, Salomonis N, Hsieh SC, Torras J, Naesens M, et al. Intragraft antiviral-specific gene expression as a distinctive transcriptional signature for studies in polyomavirus-associated nephropathy. Transplantation. 2016;100(10):2062-70.

28. O'Connell PJ, Zhang W, Menon MC, Yi Z, Schroppel B, Gallon L, et al. Biopsy transcriptome expression profiling to identify kidney transplants at risk of chronic injury: a multicentre, prospective study. Lancet. 2016;388(10048):983-93.

29. Tu Z, Wang L, Xu M, Zhou X, Chen T, genes SFF u h d g b c w h, other $\mathrm{g}$. BMC Genomics. 2006;7:31.

30. Zhu J, He F, Song S, Wang J, Yu J. How many human genes can be defined as housekeeping with current expression data? BMC Genomics. 2008;9:172.

31. She X, Rohl CA, Castle JC, Kulkarni AV, Johnson JM, Chen R. Definition, conservation and epigenetics of housekeeping and tissue-enriched genes. BMC Genomics. 2009;10:269.

32. Reverter A, Ingham A, Dalrymple BP. Mining tissue specificity, gene connectivity and disease association to reveal a set of genes that modify the action of disease causing genes. BioData Min. 2008;1(1):8.

33. Podder S, Ghosh TC. Exploring the differences in evolutionary rates between monogenic and polygenic disease genes in human. Mol Biol Evol. 2010;27(4):934-41.

34. Ramskold D, Wang ET, Burge CB, Sandberg R. An abundance of ubiquitously expressed genes revealed by tissue transcriptome sequence data. PLoS Comput Biol. 2009:5(12):e1000598.

35. Eisenberg E, Levanon EY. Human housekeeping genes, revisited. Trends Genet. 2013:29(10):569-74

36. Zyprych-Walczak J, Szabelska A, Handschuh L, Gorczak K, Klamecka K, Figlerowicz M, et al. The impact of normalization methods on RNA-Seq data analysis. Biomed Res Int. 2015;2015:621690.

37. Mortazavi A, Williams BA, McCue K, Schaeffer L, Wold B. Mapping and quantifying mammalian transcriptomes by RNA-Seq. Nat Methods. 2008;5(7): $621-8$.

38. Oshlack A, Wakefield MJ. Transcript length bias in RNA-seq data confounds systems biology. Biol Direct. 2009:4:14.

39. Dillies MA, Rau A, Aubert J, Hennequet-Antier C, Jeanmougin M, Servant N, et al. A comprehensive evaluation of normalization methods for Illumina high-throughput RNA sequencing data analysis. Brief Bioinform. 2013;14(6): $671-83$.

40. Qiu X, Hu R, Wu Z. Evaluation of bias-variance trade-off for commonly used post-summarizing normalization procedures in large-scale gene expression studies. PLoS One. 2014:9(6):e99380.

41. Shahriyari L. Effect of normalization methods on the performance of supervised learning algorithms applied to HTSeq-FPKM-UQ data sets: 7SK RNA expression as a predictor of survival in patients with colon adenocarcinoma. Brief Bioinform. 2017. https://doi.org/10.1093/bib/bbx153.

42. Mohorianu I, Bretman A, Smith DT, Fowler EK, Dalmay T, Chapman T. Comparison of alternative approaches for analysing multi-level RNA-seq data. PLoS One. 2017;12(8):e0182694. 
43. Zhang Y, Akintola OS, Liu KJA, Sun B. Membrane gene ontology bias in sequencing and microarray obtained by housekeeping-gene analysis. Gene. 2016;575(2 Pt 2):559-66.

44. Butte AJ, Dzau VJ, Glueck SB. Further defining housekeeping, or "maintenance," genes focus on "a compendium of gene expression in normal human tissues". Physiol Genomics. 2001;7(2):95-6.

45. Hsiao LL, Dangond F, Yoshida T, Hong R, Jensen RV, Misra J, et al. A compendium of gene expression in normal human tissues. Physiol Genomics. 2001;7(2):97-104.

46. Thellin O, Zorzi W, Lakaye B, De Borman B, Coumans B, Hennen G, et al. Housekeeping genes as internal standards: use and limits. J Biotechnol. 1999;75(2-3):291-5.

47. Barber RD, Harmer DW, Coleman RA, Clark BJ. GAPDH as a housekeeping gene: analysis of GAPDH mRNA expression in a panel of 72 human tissues. Physiol Genomics. 2005;21(3):389-95.

48. de Jonge HJ, Fehrmann RS, de Bont ES, Hofstra RM, Gerbens F, Kamps WA, et al. Evidence based selection of housekeeping genes. PLoS One. 2007;2(9):e898.

49. Caracausi M, Piovesan A, Antonaros F, Strippoli P, Vitale L, Pelleri MC Systematic identification of human housekeeping genes possibly useful as references in gene expression studies. Mol Med Rep. 2017;16(3):2397-410.

\section{Publisher's Note}

Springer Nature remains neutral with regard to jurisdictional claims in published maps and institutional affiliations.

Ready to submit your research? Choose BMC and benefit from:

- fast, convenient online submission

- thorough peer review by experienced researchers in your field

- rapid publication on acceptance

- support for research data, including large and complex data types

- gold Open Access which fosters wider collaboration and increased citations

- maximum visibility for your research: over $100 \mathrm{M}$ website views per year

At BMC, research is always in progress.

Learn more biomedcentral.com/submissions 